\title{
Structural Basis for Inhibition of Human Primase by Arabinofuranosyl Nucleoside Analogues Fludarabine and Vidarabine
}

\author{
Sandro Holzer, ${ }^{\dagger}$ Neil J. Rzechorzek, ${ }^{\dagger}$ Isobel R. Short, $^{\dagger}$ Michael Jenkyn-Bedford, ${ }^{\dagger}$ Luca Pellegrini, ${ }^{\dagger} \odot$
} and Mairi L. Kilkenny* ${ }^{*} \dagger$

${ }^{\dagger}$ Department of Biochemistry, University of Cambridge, 80 Tennis Court Road, Cambridge CB2 1GA, U.K.

\section{Supporting Information}

ABSTRACT: Nucleoside analogues are widely used in clinical practice as chemotherapy drugs. Arabinose nucleoside derivatives such as fludarabine are effective in the treatment of patients with acute and chronic leukemias and non-Hodgkin's lymphomas. Although nucleoside analogues are generally known to function by inhibiting DNA synthesis in rapidly proliferating cells, the identity of their in vivo targets and mechanism of action are often not known in molecular detail. Here we provide a structural basis for arabinose nucleotide-mediated inhibition of human primase, the DNA-dependent RNA polymerase responsible for initiation of DNA synthesis in DNA replication. Our data suggest ways in which the chemical structure of fludarabine could be modified to improve its specificity and affinity toward primase, possibly leading to less toxic and more effective therapeutic agents.

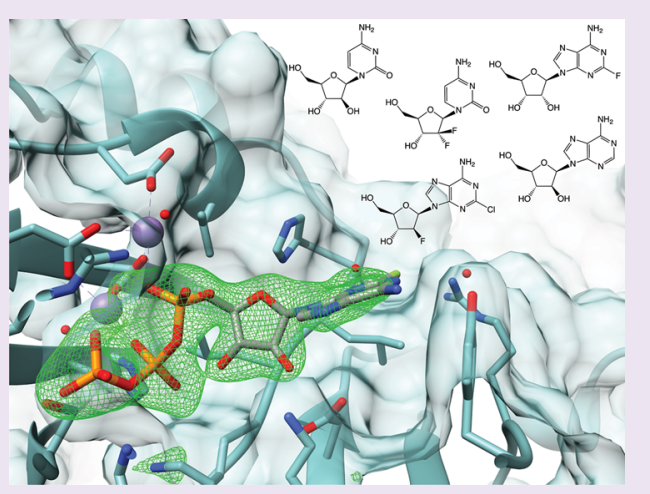

$\mathrm{P}$ rior to cell division, cells must accurately duplicate their genetic material to ensure that both daughter cells contain a full complement of genes. The process of DNA replication is carried out by a large and dynamic macromolecular assembly known as the replisome, which coordinates unwinding of the DNA duplex with DNA synthesis of both leading and lagging strands. ${ }^{1}$ Because replicative DNA polymerases cannot initiate the synthesis of new DNA, they rely on a DNA-dependent RNA polymerase known as primase to produce short RNA oligonucleotides that act as primers. ${ }^{2}$ Primase therefore plays an essential role in DNA replication, priming the synthesis of both the leading and lagging strand.

Human primase is a heterodimeric enzyme comprising two subunits: Pri1 (49.9 kDa, also known as PriS or p49) and Pri2 (58.8 kDa, also known as PriL or p58), encoded by the PRIM1 and PRIM2 genes, respectively. ${ }^{3}$ PRIM1 maps to a region of chromosome 12 that is amplified in numerous tumor types., ${ }^{4,5}$ In addition, elevated PRIM1 expression has been observed in breast tumor tissues, correlating with poorer patient outcomes. ${ }^{6}$ While PRIM1 has long been known to be an essential gene in eukaryotic cells, ${ }^{2}$ more recently a CRISPR genomewide dropout screen identified PRIM1 as an essential gene in all 7 cancer cell lines tested. ${ }^{7}$ It has therefore been suggested that primase may represent an effective target for anticancer therapy. $^{6-9}$

Many anticancer agents in clinical use interfere with tumor growth by inhibiting DNA replication. A subset of these replication inhibitors, known as nucleoside analogues, comprises a series of pyrimidine and purine nucleoside antimetabolites that are widely used in the treatment of hematological malignancies and solid tumors. ${ }^{10,11}$ These compounds include fludarabine (2F-araAMP), vidarabine ( $\operatorname{araA})$, cytarabine (araC), cladribine (2Cl-dA), gemcitabine $\left(2^{\prime}, 2^{\prime}-\mathrm{diF}-\mathrm{dC}\right)$, and clofarabine $\left(2 \mathrm{Cl}-2^{\prime} \mathrm{F}\right.$-aradA $)$. Upon cellular uptake, these analogues are biologically activated by $5^{\prime}$ triphosphorylation. They subsequently elicit their effects by directly inhibiting intracellular enzymes and/or by retarding or terminating nucleic acid synthesis as they are incorporated into nascent DNA and RNA strands. ${ }^{11,12}$

Vidarabine triphosphate (vidarabine-TP) and fludarabine triphosphate (fludarabine-TP) are both ATP analogues in which the $2^{\prime}$-hydroxyl is in the arabino (ara) rather than the ribo configuration (Figure 1A). Vidarabine, while no longer used as a cancer treatment due to its rapid deamination in vivo, is nonetheless effective as an antiviral agent against herpes simplex virus and varicella zoster virus infections. ${ }^{13}$ Fludarabine, which is more resistant to deamination, is widely used as a chemotherapeutic agent to treat B-cell chronic lymphocytic leukemia (CLL), acute myeloid leukemia (AML), and some types of non-Hodgkin's lymphoma. ${ }^{14,15}$ However, treatment is often associated with thrombocytopenia, anemia, neutropenia, and profound lymphopenia, thereby increasing the risk of opportunistic infections. ${ }^{16,17}$ In fact, one of the major problems with the therapeutic use of current nucleoside analogues is dose-limiting toxicity due to their nonselective nature, with

Received: May 8, 2019

Accepted: September 3, 2019

Published: September 3, 2019 
A<smiles></smiles>

2F-ATP

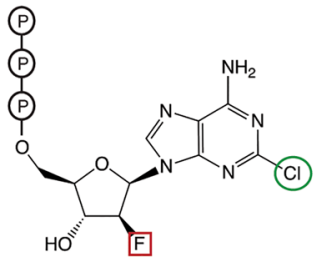

clofarabine-TP

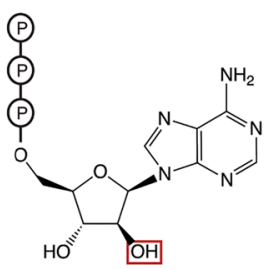

vidarabine-TP

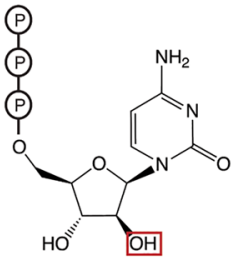

cytarabine-TP

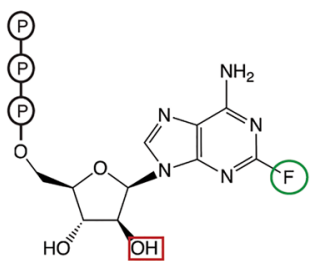

fludarabine-TP

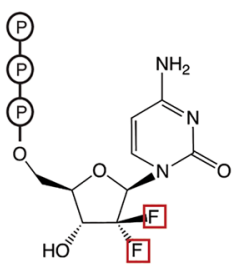

gemcitabine-TP
B

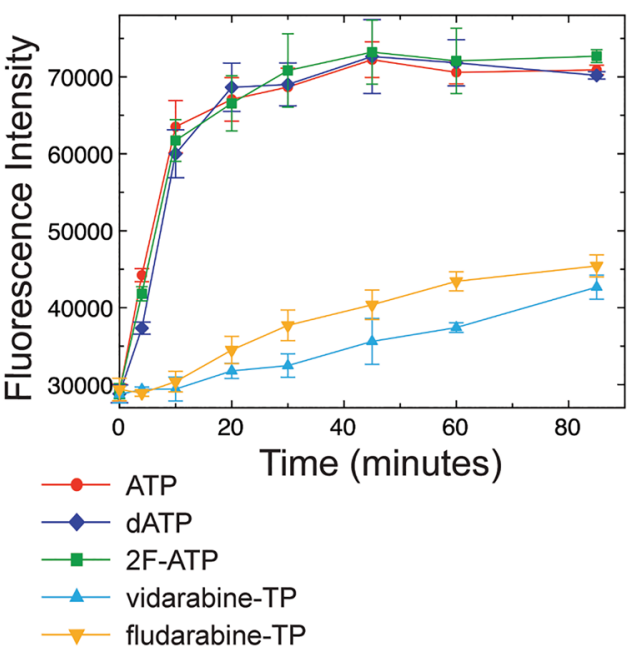

Figure 1. ara nucleotides inhibit RNA primer synthesis by human primase. a) Chemical structures of the nucleotide analogues used in this study. Structures were generated using ChemDraw 18.0. b) Fluorescence-based RNA primer synthesis assay on a ssDNA template (5'GTTGTCCATTATGTCCTACCTCGTGCTCCT) in the presence of $1 \mathrm{mM} \mathrm{Mn}^{2+}$ ions and equimolar concentrations of ribonucleotides (20 $\mu \mathrm{M}$ each rNTP) and the indicated nucleotide analogue $(20 \mu \mathrm{M})$. Each data point represents the mean $\pm \mathrm{SD}(n=3)$. Curves are colored as follows: ATP (red), dATP (navy), 2F-ATP (green), vidarabine-TP (light blue), and fludarabine-TP (orange).

potential targets including DNA and RNA polymerases, ribonucleotide reductase, and DNA ligase. ${ }^{18-24}$

Vidarabine-TP and fludarabine-TP are potent inhibitors of DNA replication in vivo ${ }^{25}$ and have been shown to inhibit both replicative DNA polymerases and primase in vitro. ${ }^{26-28}$ Primase incorporates ara nucleotides into primers more efficiently than normal ribonucleotides, ${ }^{29-31}$ and it has been suggested that primase inhibition may be one of the primary mechanisms for fludarabine cytotoxicity in tumor cells. ${ }^{29,32,33}$ However, deciphering which of the many nucleotide-binding enzymes are the primary targets of the ara nucleotides in vivo has proved difficult, with the result that their mechanism of cytotoxicity is still unclear.

A drug that selectively inhibits primase without significant off-target effects could be of significant therapeutic value and may be less toxic to nondividing cells. ${ }^{34}$ Importantly, recent structural information has made the design of high affinity primase inhibitors a more realistic prospect. ${ }^{35,36}$ Here we test the effect of a range of chemotherapeutic nucleoside analogues on primase activity. We also present the crystal structures of human Pril bound to vidarabine-TP and fludarabine-TP, thereby elucidating the mode of binding of arabinofuranosyl nucleotides to the catalytic subunit of primase and explaining the reported preference of primase for these nucleotides. We propose that these ara nucleotides represent an interesting starting point for the structure-based drug design of specific primase inhibitors.

\section{RESULTS AND DISCUSSION}

Inhibition of RNA Primer Synthesis by Vidarabine-TP and Fludarabine-TP. To confirm that ara nucleotides are effective inhibitors of human primase, we analyzed their effect on RNA primer synthesis. A fluorescence-based RNA primer synthesis assay ${ }^{37}$ revealed strong inhibition of primase activity by both vidarabine-TP and fludarabine-TP (Figure 1B). While similar levels of inhibition were observed for both compounds, no inhibition was observed in the presence of 2F-ATP, confirming that it is the arabinofuranosyl moiety that is important for mediating the inhibitory effect of these nucleotide analogues. Inhibition occurred irrespective of whether the divalent metal was $\mathrm{Mn}^{2+}$ (Figure $1 \mathrm{~B}$ ) or $\mathrm{Mg}^{2+}$ (Supplementary Figure 1A). While both divalent metals support robust primer synthesis in vitro, $\mathrm{Mn}^{2+}$ has been reported not only to enhance the binding of nucleotides to human primase but also to reduce the fidelity of various polymerases including primase. ${ }^{36,38,39}$

These results were confirmed using denaturing gel electrophoresis to analyze the priming reaction products synthesized in the presence of increasing concentrations of fludarabine-TP (Figure 2A). We observed strong dose-dependent inhibition of RNA primer synthesis, with near complete inhibition evident at $200 \mu \mathrm{M}$ fludarabine-TP and $500 \mu \mathrm{M}$ ATP. In the presence of an existing RNA primer annealed to a single-stranded DNA template, providing primase with fludarabine-TP as the only available nucleotide limited primer extension to one or two nucleotides (Figure 2B). Primase added the first fludarabine moiety quickly (lane 4 , first addition complete by $2 \mathrm{~min}$ ) and the second much more slowly (lane 7, second addition complete by $30 \mathrm{~min}$ ). An RNA primer with fludarabine incorporated at its 3 -end could not be further extended with ATP, suggesting that incorporation and capping of the growing ribonucleotide chain is a likely mechanism of action (Figure $2 \mathrm{C}$ ). This is in agreement with previous primase studies which also describe chain termination by ara nucleotides. ${ }^{22,29,40}$

We then used a fluorescence polarization (FP) competition binding assay to compare the binding affinities of the various nucleotide analogues. In this experiment, the binding of 6FAM-labeled ATP to Pril was challenged by titrating in the various nucleotide analogues. Given the addition of an unnatural fluorescent label, we first confirmed that 6FAMATP still bound exclusively to the nucleotide binding pocket on Pri1, with no nonspecific binding (Supplementary Figure 1B). The lower $K_{1 / 2}$ values obtained for the ara nucleotides $\left(K_{1 / 2}\right.$ fludarabine-TP $\left.^{2}=1.1 \mu \mathrm{M}, K_{1 / 2}{ }^{\text {vidarabine-TP }}=1.5 \mu \mathrm{M}\right)$ compared to those for the ribo/deoxyribonucleotides $\left(K_{1 / 2}{ }^{\text {ATP }}=7.5 \mu \mathrm{M}\right.$, $\left.K_{1 / 2}^{2 \mathrm{~F}-\mathrm{ATP}}=7.2 \mu \mathrm{M}, K_{1 / 2}{ }^{\mathrm{dATP}}=3.3 \mu \mathrm{M}\right)$ indicate that the ara 
A
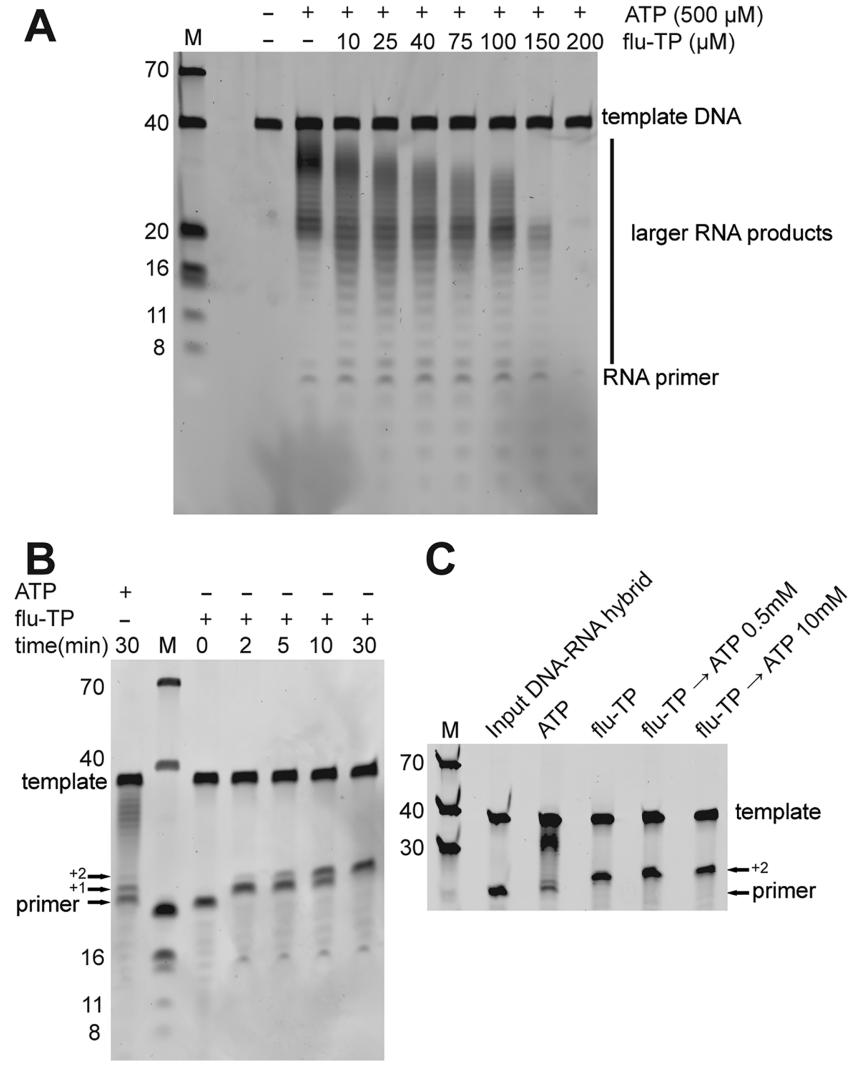

Figure 2. Effect of fludarabine-TP on RNA primer synthesis. a) Denaturing gel showing the dose-dependent inhibition of RNA primer synthesis by fludarabine-TP (flu-TP). Reactions contained 0.5 $\mu \mathrm{M}$ polydT40 ssDNA template, $0.5 \mu \mathrm{M}$ primase, $500 \mu \mathrm{M}$ ATP, 10 $\mathrm{mM} \mathrm{Mg}(\mathrm{OAc})_{2}$, and the indicated concentration of flu-TP. Reactions were incubated at $37{ }^{\circ} \mathrm{C}$ for $30 \mathrm{~min}$. b) Denaturing gel showing the incorporation of fludarabine into an existing RNA primer. The template comprised a 38-mer DNA template $\left(5^{\prime}-\mathrm{T}_{20}\right.$ CCAGAGAGCGCCCAAACG) annealed to an 18-mer RNA primer (5'-CGUUUGGGCGCUCUCUGG). Reactions contained $0.5 \mu \mathrm{M}$ annealed DNA-RNA template, $0.5 \mu \mathrm{M}$ primase, $10 \mathrm{mM} \mathrm{Mg}(\mathrm{OAc})_{2}$, and 500 $\mu \mathrm{M}$ ATP or flu-TP. Reactions were incubated at $37{ }^{\circ} \mathrm{C}$ for the indicated time. c) Denaturing gel showing that primase is unable to extend an RNA primer following fludarabine incorporation. $0.5 \mu \mathrm{M}$ primase was incubated with $0.5 \mu \mathrm{M} \mathrm{DNA}(38)-\mathrm{RNA}(18)$ template and either $500 \mu \mathrm{M}$ ATP (lane 3) or $500 \mu \mathrm{M}$ flu-TP (lane 4) for 30 min at $37{ }^{\circ} \mathrm{C}$. ATP $(0.5$ or $10 \mathrm{mM})$ was subsequently added to the flu-TP sample and incubated for a further $30 \mathrm{~min}$ (lanes 5, 6). All gels were poststained with Sybr Gold. $\mathrm{M}=$ marker.

nucleotides indeed bind with higher affinity (Figure 3A). Using thermal denaturation, we observed that all nucleotides stabilized primase relative to the unliganded enzyme (Figure 3B). While both ara nucleotides stabilized primase to a greater extent relative to ATP, fludarabine-TP imparted far greater thermal stability than vidarabine-TP $\left(T_{\mathrm{m}}{ }^{\mathrm{ATP}}=53.8 \pm 0.3{ }^{\circ} \mathrm{C}\right.$, $T_{\mathrm{m}}$ vidarabine-TP $=54.4 \pm 0.2{ }^{\circ} \mathrm{C}, T_{\mathrm{m}}$ fludarabine-TP $\left.=58.0 \pm 0.2{ }^{\circ} \mathrm{C}\right)$.

Crystal Structures of Fludarabine-TP and VidarabineTP Bound to Pri1. Primase initiates RNA primer synthesis using two distinct nucleotide binding pockets: (i) the initiation site, which utilizes several key residues on Pri2-CTD to bind the first nucleotide that forms the 5 -end of the RNA primer, and (ii) the Pril elongation site that binds all subsequent nucleotides and adds them to the $3^{\prime}$-end of the growing primer. ${ }^{41,42}$ Following synthesis of the first dinucleotide, which involves both Pri1 and Pri2, further nucleotide addition

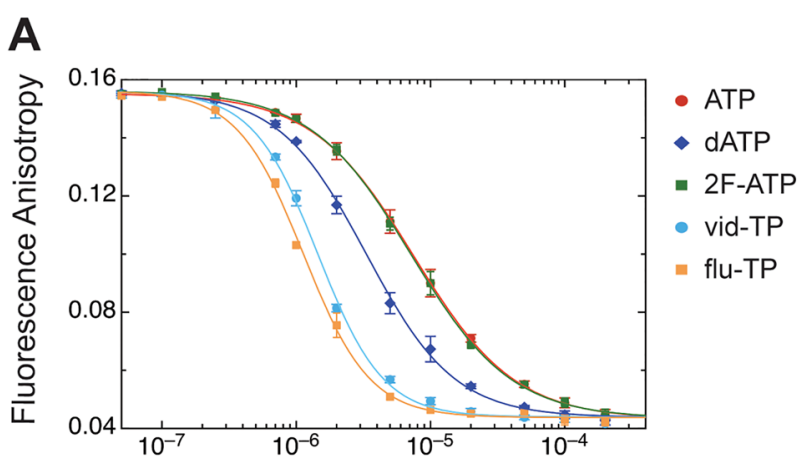

Nucleotide Concentration (M)

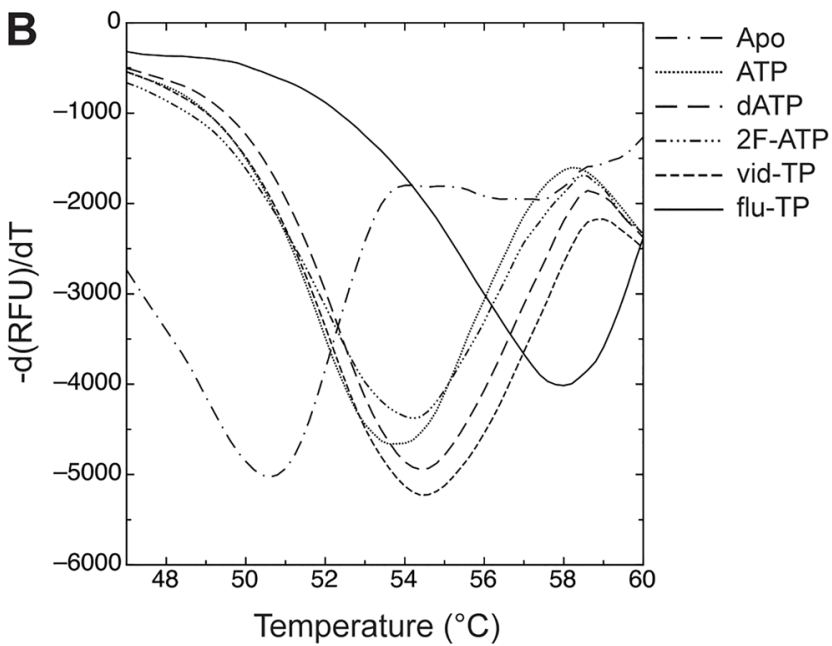

Figure 3. ara nucleotides show enhanced binding to and stabilization of human primase. a) FP-based competition binding experiment in which 6FAM-ATP $(30 \mathrm{nM})$ in the presence of excess Pril $(1.5 \mu \mathrm{M})$ was challenged with increasing concentrations of the indicated nucleotide. Each data point represents the mean $\pm \operatorname{SD}(n=3)$. b) First derivative of the thermal denaturation curve for the chimeric Pri1-Pri2 ${ }^{\Delta \text { CTD }}$-Pol $\alpha$ construct (see Methods) in the presence of the indicated nucleotide or nucleotide analogue. Single, representative curves are shown. Calculated melting temperatures: $T_{\mathrm{m}}{ }^{\text {Apo }}(50.5 \pm 0.2$ $\left.{ }^{\circ} \mathrm{C}\right), T_{\mathrm{m}}{ }^{\text {ATP }}\left(53.8 \pm 0.3{ }^{\circ} \mathrm{C}\right), T_{\mathrm{m}}{ }^{\mathrm{dATP}}\left(54.5 \pm 0.1{ }^{\circ} \mathrm{C}\right), T_{\mathrm{m}}{ }^{2 \mathrm{~F}-\mathrm{ATP}}(54.3$ $\left.\pm 0.1{ }^{\circ} \mathrm{C}\right), T_{\mathrm{m}}{ }^{\text {vid-TP }}\left(54.4 \pm 0.2^{\circ} \mathrm{C}\right), T_{\mathrm{m}}{ }^{\text {flu-TP }}\left(58.0 \pm 0.2^{\circ} \mathrm{C}\right)($ mean \pm $\mathrm{SD}, n=4)$. RFU: relative fluorescence units.

requires only the elongation site on Pri1..$^{43,44}$ To obtain atomic details of the interaction between ara nucleotides and the elongation site of human Pril, we soaked vidarabine-TP and fludarabine-TP into Pril crystals that diffracted to high resolution and in which the active site was free from lattice contacts. For comparison, we determined in the same way the crystal structures of Pril bound to ATP, 2F-ATP, and dATP. Given the higher affinity of Pril for ATP in the presence of $\mathrm{Mn}^{2+}\left(K_{\mathrm{d}}{ }^{6 \mathrm{FAM}-\mathrm{ATP}}=0.41 \mu \mathrm{M}\right.$, Supplementary Figure 1C) compared to $\mathrm{Mg}^{2+}$, we supplemented the nucleotidecontaining crystal soak solutions with $500 \mu \mathrm{M} \mathrm{MnCl}_{2}$. Data collection and refinement statistics are given in Table 1. For each nucleotide soak, a Fo-Fc omit map clearly revealed a single nucleotide bound to the elongation pocket of Pri1 (Supplementary Figure 2A-E). Final 2Fo-Fc electron density maps for each of the nucleotides are shown in Figure 4A.

This high resolution structural information allowed us to compare in detail the interactions of the different sugar moieties with the Pril active site. As described previously, human Pril adopts the mixed $\alpha / \beta$ primase (Prim) fold 
Table 1. Data Collection and Refinement Statistics for the Crystal Structures of Pril Bound to Nucleotides and Nucleotide Analogues $^{a}$

\begin{tabular}{|c|c|c|c|c|c|}
\hline & ATP & dATP & 2F-ATP & Vid-TP & Flu-TP \\
\hline $\begin{array}{l}\text { accession code } \\
\text { data collection }\end{array}$ & \multicolumn{5}{|c|}{ data collection } \\
\hline wavelength ( & 0.979 & 0.917 & 1.039 & 0.979 & 0.979 \\
\hline $\begin{array}{l}\text { space group } \\
\text { cell dimensions }\end{array}$ & \multicolumn{4}{|c|}{ cell dimensions } & $C 222_{1}$ \\
\hline$a, b, c(\AA)$ & $110.1,117.3,151.2$ & $110.5,117.3,151.7$ & $110.5,117.2,152.1$ & $111.1,119.0,150.7$ & $110.8,117.6,148.8$ \\
\hline$\alpha, \beta, \gamma\left(^{\circ}\right)$ & $90,90,90$ & $90,90,90$ & $90,90,90$ & $90,90,90$ & $90,90,90$ \\
\hline $\begin{array}{l}\text { molecules/asymmetric } \\
\text { unit }\end{array}$ & 2 & 2 & 2 & 2 & 2 \\
\hline resolution $(\AA)$ & $29.32-2.75(2.91-2.75)$ & $46.40-1.95(2.07-1.95)$ & $46.41-1.85(1.96-1.85)$ & $46.69-2.35(2.49-2.35)$ & $46.13-2.20(2.33-2.20)$ \\
\hline unique reflections & $25616(2462)$ & $71418(11299)$ & $82430(12971)$ & $41814(6609)$ & $49380(7541)$ \\
\hline$R_{\text {meas }}$ & $0.18(0.92)$ & $0.09(1.20)$ & $0.08(0.77)$ & $0.08(1.05)$ & $0.10(1.38)$ \\
\hline mean $I / \sigma I$ & $5.46(1.04)$ & $14.56(1.33)$ & $11.52(1.52)$ & $15.35(1.63)$ & $12.91(1.52)$ \\
\hline completeness, \% & $96.8(94.5)$ & $99.2(98.0)$ & $97.7(95.8)$ & $99.7(98.7)$ & $99.2(95.3)$ \\
\hline redundancy & 4.95 & 6.75 & 4.39 & 7.20 & 6.50 \\
\hline $\mathrm{CC}_{1 / 2}$ & $0.98(0.36)$ & $1.00(0.75)$ & $1.00(0.77)$ & $1.00(0.81)$ & $1.00(0.83)$ \\
\hline Wilson B-factor & 67.09 & 37.03 & 34.23 & 62.01 & 44.70 \\
\hline \multicolumn{6}{|l|}{ Refinement } \\
\hline non-hydrogen atoms & 6541 & 7033 & 7007 & 6638 & 6734 \\
\hline$R_{\text {work }} / R_{\text {free }}, \%$ & $22.8 / 26.9$ & $17.8 / 21.5$ & $17.8 / 20.6$ & $20.9 / 23.9$ & $19.6 / 22.3$ \\
\hline average $\mathrm{B}$ factor & 71.36 & 49.46 & 45.47 & 81.21 & 57.34 \\
\hline clashscore & 2.79 & 1.36 & 1.51 & 1.46 & 1.31 \\
\hline $\begin{array}{l}\text { rotamer outliers, \% } \\
\text { rmsd }\end{array}$ & 0.56 & 0.27 & 0.41 & 0.00 & 0.83 \\
\hline bond lengths & 0.004 & 0.003 & 0.003 & 0.004 & 0.003 \\
\hline bond angles & 0.63 & 0.63 & 0.66 & 0.68 & 0.53 \\
\hline \multicolumn{6}{|l|}{ Ramachandran analysis } \\
\hline preferred region, \% & 96.83 & 96.71 & 97.09 & 96.98 & 97.22 \\
\hline allowed regions, \% & 3.17 & 3.15 & 2.91 & 3.02 & 2.78 \\
\hline outliers, $\%$ & 0.00 & 0.13 & 0.00 & 0.00 & 0.00 \\
\hline
\end{tabular}

characteristic of eukaryotic and archaeal primases, with a catalytic triad comprising Asp109, Asp111, and Asp306 which together coordinate two divalent metal ions. ${ }^{35,45}$ As seen in previous nucleotide-bound Pril crystal structures, the triphosphate moiety of the nucleotide resides in a basic pocket formed by the side chains of residues Arg162, Arg163, His166, Lys318, and His324, as well as the two $\mathrm{Mn}^{2+}$ ions coordinated by the catalytic aspartates (Supplementary Figure 2F). ${ }^{35,36}$ By superposing the apo and nucleotide-bound structures, we observe that the loop containing Asp306 needs to move toward the active site to allow the Asp306 side chain to coordinate the second $\mathrm{Mn}^{2+}$ ion effectively (Figure 4B). Interestingly, while the ATP, dATP, 2F-ATP, and fludarabineTP structures show a fully engaged loop, the vidarabine-TP structure reveals the loop to adopt an intermediate or apo conformation, and the second $\mathrm{Mn}^{2+}$ ion could not be reliably modeled for either chain of the asymmetric unit (Figure 4A).

In all structures, the sugar moiety is positioned by the formation of a hydrogen bond between the ribose $3^{\prime}-\mathrm{OH}$ and the main-chain amide $\mathrm{NH}$ of Lys318 (Figure 4C). This interaction is important for catalysis because cordycepin-TP ( $3^{\prime}$-deoxyadenosine triphosphate) is not efficiently polymerized onto an existing RNA primer and only starts to inhibit RNA primer synthesis when present in excess of ATP (Supplementary Figure 3). In addition to this hydrogen bond, $\mathrm{C} 4$ and $\mathrm{C} 5$ of the ribose moiety pack on top of the aliphatic side chain of Leu317. In the ATP- and 2F-ATP- bound structures, the $2^{\prime}-\mathrm{OH}$ of the ribose inserts between the main-chain carbonyl group of Leu316 and the carboxylate group of the Asp79 side chain and is positioned roughly equidistant between these two moieties. However, in the vidarabine-TP and fludarabine-TP bound structures, the 2 '$\mathrm{OH}$ points directly toward the carboxylate group of Asp79 and the $\varepsilon$-amino group of Lys77 and away from the carbonyl $O$ of Leu316 (Figure 4C). In this way, the ara nucleotides present the $2^{\prime}-\mathrm{OH}$ in an orientation that is more favorable for hydrogen bond formation compared to the normal ribonucleotides. The fluorine atom on the base moiety of fludarabine-TP resides above the side chain of Leu316 (Figure 4C) and only 3.6-3.9 $\AA$ away from the side chain of the catalytically essential residue Arg56. ${ }^{35}$ This conserved and catalytically crucial pocket could certainly be explored further in future structure-based drug design efforts.

The vidarabine-TP and fludarabine-TP crystal structures indicate that the side chain of residues Lys77 and/or Asp79 may be responsible for the observed preference of primase for ara nucleotides. We attempted to confirm this using Pri1 mutagenesis. While the K77A mutant behaved as wild-type, the D79A point mutant did show a slight weakening of the interaction between Pril and ara nucleotide (data not shown). However, we suspect the analysis may be complicated by partial redundancy between the two side chains and/or a more complex binding mode which will require further investigation. 


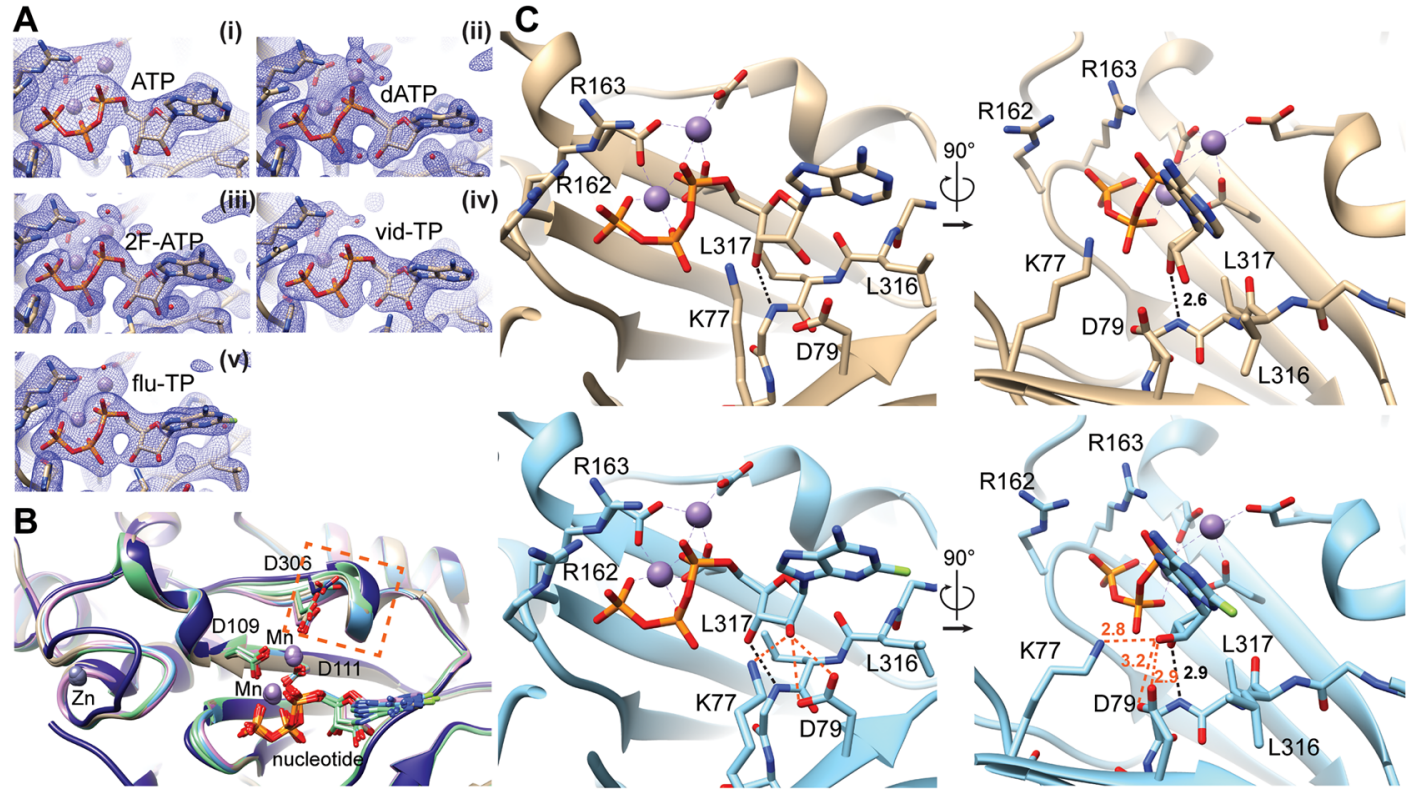

Figure 4. Nucleotide binding to the elongation pocket of Pri1. a) 2Fo-Fc electron density maps (contoured at $1.0 \sigma$ ) showing the elongation site of Pril in complex with $\mathrm{Mn}^{2+}$ ions (purple spheres) and (i) ATP, (ii) dATP, (iii) 2F-ATP, (iv) vidarabine-TP (vid-TP), or (v) fludarabine-TP (fluTP). b) Superposition of the crystal structures of apo and nucleotide-bound Pril. Superposition shows the elongation site of apo Pril (navy blue) and in complex with ATP (beige), dATP (purple), 2F-ATP (pink), vid-TP (green), and flu-TP (light blue). Mn ${ }^{2+}$ ions are shown as purple spheres, and $\mathrm{Zn}^{2+}$ ions are shown as gray spheres. Both Pril chains in the asymmetric unit of the nucleotide-bound structures are shown. c) The elongation site of Pril bound to ATP (beige) and flu-TP (blue). In both structures the ribose 3'-OH forms a hydrogen bond to the main chain $\mathrm{NH}$ group of Lys 318 (dashed line, black; Lys318 side chain removed for clarity). In the flu-TP structure the ara $2^{\prime}$-OH is poised to interact with the side chains of Asp79 and/or Lys77 (dashed lines, orange). Numbers indicate measured hydrogen bond distances in Å. All images were generated using Chimera. ${ }^{53}$

The ara $2^{\prime}-\mathrm{OH}$ Is Crucial for Mediating Effective Primase Inhibition. To investigate whether primase inhibition is a shared property of chemotherapeutic nucleotide analogues, we examined RNA primer synthesis activity in the presence of an extended repertoire of these agents, including gemcitabine-TP, cytarabine-TP, and clofarabine-TP (Figure 1A). On a ssDNA template, titration of cytarabine-TP resulted in very similar levels of primase inhibition to fludarabine-TP (Figure 5A). Given that cytarabine-TP and fludarabine-TP are CTP and ATP analogues, respectively, this experiment was conducted using a ssDNA template containing equal quantities of $\mathrm{T}$ and $\mathrm{G}$. This result was corroborated in a fluorescencebased primer synthesis assay, which showed similar levels of inhibition for fludarabine-TP, vidarabine-TP, and cytarabineTP (Figure 5B). In addition, cytarabine was readily incorporated into an existing RNA primer, as described previously (Supplementary Figure 4B). ${ }^{40}$ These results further confirm that primase inhibition by ara $2^{\prime}-\mathrm{OH}$ nucleotide analogues is largely unaffected by the nature of the base moiety.

By contrast, gemcitabine-TP and clofarabine-TP, which both contain an ara $2^{\prime}$-F rather than ara $2^{\prime}-\mathrm{OH}$, did not inhibit RNA primer synthesis over the range of concentrations tested (Figure 5C). In addition, in an FP-based competition binding experiment, gemcitabine-TP and clofarabine-TP produced very similar $K_{1 / 2}$ values to ATP (Supplementary Figure $4 \mathrm{~A}$ ). This is consistent with the structural data presented here, as an ara $2^{\prime}$ $\mathrm{F}$ would be unable to form a favorable hydrogen bond with the carboxylate side chain of Asp79. Interestingly, in the presence of nucleotide analogue alone, while clofarabine was poorly incorporated into an existing RNA primer, gemcitabine was readily incorporated (Supplementary Figure 4B). We conclude that, while primase can incorporate gemcitabine into RNA primers, this analogue does not exert significant inhibition of primer synthesis in the presence of the natural ribonucleotides. This is probably due to its weaker binding affinity compared to the ara $2^{\prime}-\mathrm{OH}$ nucleotide analogues. Taken together, these results indicate that a hydrogen bond donor in the $2^{\prime}$ position of the arabinose sugar moiety is crucial for mediating effective primase inhibition by these nucleotide analogues.

In conclusion, we have analyzed in detail the mode of binding of anticancer agent fludarabine-TP and antiviral agent vidarabine-TP to human Pril. Thermal denaturation, competition, and primer synthesis experiments all confirm that these arabinofuranosyl nucleotides are bona fide inhibitors of primase, as is the CTP-analogue, cytarabine-TP. Given that these ara nucleotides inhibit primase to a significant degree in the presence of excess normal ribonucleotides in vitro (Figure 2A, Figure 5A) and the fact that fludarabine-TP can accumulate to concentrations in the range of hundreds of micromolar inside cells, ${ }^{46}$ it is possible that primase may indeed be one of the relevant targets of this chemotherapeutic agent in vivo. Whether primase inhibition by fludarabine-TP or cytarabine-TP is one of the primary modes of cytotoxicity toward cancer cells remains to be determined and will be the subject of future experiments.

Gemcitabine, cytarabine, fludarabine, and clofarabine are all used as cytotoxic anticancer agents in the clinic, but despite structural similarities, their mode of action and in vivo stability seems to vary quite significantly. ${ }^{47}$ Recently, human PrimPol (a second human primase, involved in translesion synthesis) was shown to incorporate cytarabine-TP and gemcitabine-TP, but not two antiviral nucleoside analogues (emtricitabine and lamivudine), into newly synthesized DNA strands. ${ }^{48}$ These 

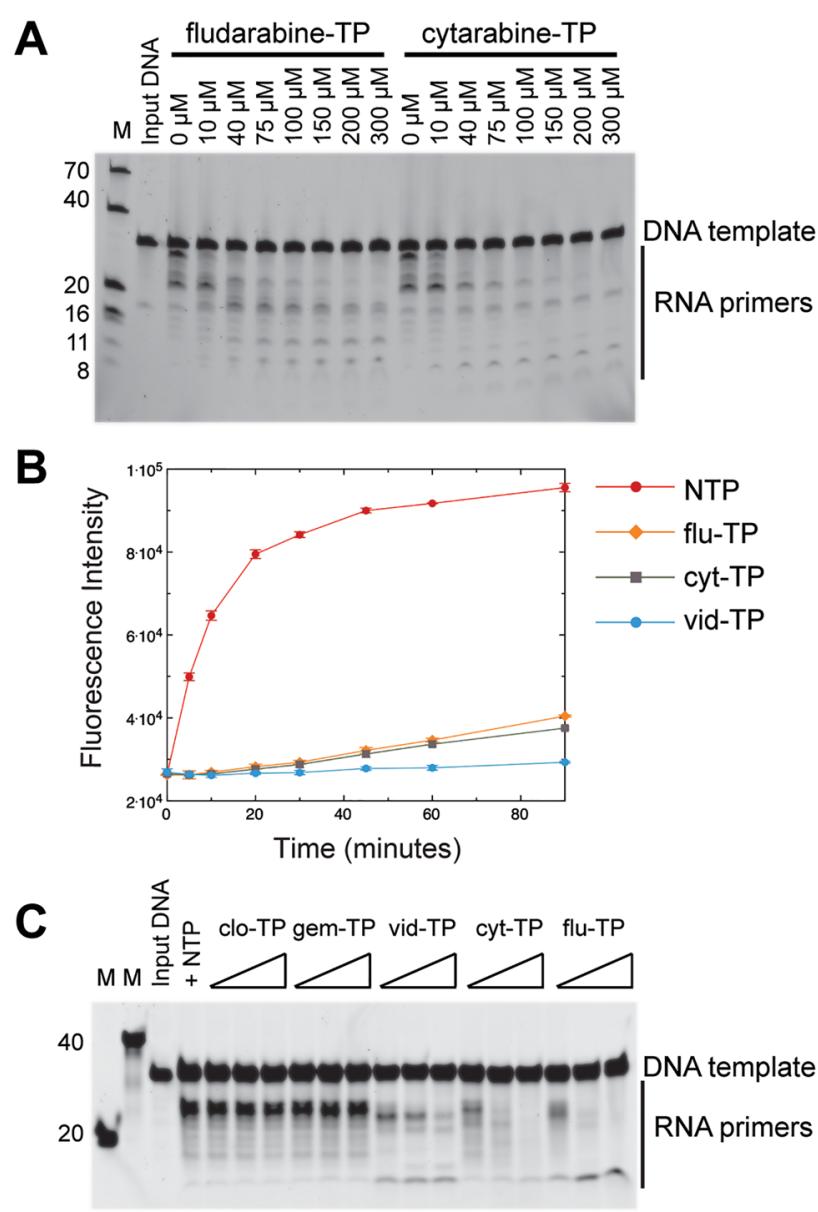

Figure 5. ara $2^{\prime}-\mathrm{OH}$ but not ara $2^{\prime}-\mathrm{F}$ nucleotide analogues mediate efficient inhibition of RNA primer synthesis. a) Denaturing gel showing the effect of fludarabine-TP and cytarabine-TP on RNA primer synthesis. Reactions contained $0.5 \mu \mathrm{M}$ primase, $0.5 \mu \mathrm{M}$ ssDNA template (5'-ATGAGTGAATGTCTGTGAGTGTCTGCCTGC), $500 \mu \mathrm{M}$ each $\mathrm{NTP}, 10 \mathrm{mM} \mathrm{Mg}(\mathrm{OAc})_{2}$, and the indicated concentration of nucleotide analogue. Reactions were incubated at 37 ${ }^{\circ} \mathrm{C}$ for $30 \mathrm{~min}$. b) Fluorescence-based RNA primer synthesis assay on the same ssDNA template described in (a) above, in the presence of 1 $\mathrm{mM} \mathrm{Mn}{ }^{2+}$ ions, and equimolar concentrations of ribonucleotides (20 $\mu \mathrm{M}$ each NTP) and nucleotide analogue $(20 \mu \mathrm{M})$ : fludarabine-TP (flu-TP), cytarabine-TP (cyt-TP), or vidarabine-TP (vid-TP). Each data point represents the mean $\pm \mathrm{SD}(n=3)$. c) Denaturing gel showing the effect of the $2^{\prime}-\mathrm{F}$ ara nucleotide analogues, clofarabineTP (clo-TP) and gemcitabine-TP (gem-TP), on RNA primer synthesis. Reactions contained $1 \mu \mathrm{M}$ ssDNA template (5'- GTTGTCCATTATGTCCTACCTCGTGCTCCT), $0.5 \mu \mathrm{M}$ primase, 500 $\mu \mathrm{M}$ each NTP, $10 \mathrm{mM} \mathrm{Mg}(\mathrm{OAc})_{2}$, and the indicated concentration of nucleotide analogue $(25,100$, or $500 \mu \mathrm{M})$. Reactions were incubated as in (a). $M=$ marker.

studies highlight how important it will be to analyze the effect of each nucleotide analogue on a range of intracellular targets in order to begin to understand their nuanced activity in vivo.

The data presented here indicate that chemotherapeutic nucleotides cytarabine-TP and fludarabine-TP, but not gemcitabine-TP or clofarabine-TP, are likely to be effective inhibitors of primase activity in vivo. They bind more tightly to the elongation pocket of human Pril than the natural nucleotides (Figure 3A), and in the context of the fully functional Pri1-Pri2 heterodimer, these ara nucleotides are efficiently incorporated into RNA primers (Figure 2B, Supplementary Figure 4B) and have the potential to induce chain termination of nascent RNA primers (Figure 2C). Thus, it is likely that their inhibitory action is a result of both competitive inhibition and capping of the RNA primer resulting in chain termination.

It should now be possible to build on previous work outlining the synthesis of novel ara nucleotide analogue compounds as potent primase inhibitors. ${ }^{34}$ Initial work was promising, describing a nucleotide analogue (araBTP) with improved selectivity for primase over DNA polymerase $\alpha$, but further advances were hindered by a lack of structural information relating to the mode of binding of this agent to the primase active site. Based on the structural data presented here, we hypothesize that it should be possible to further optimize the binding of ara nucleotides to Pril, in order to generate a higher affinity, more selective inhibitor of human primase. This may result in a new chemotherapeutic agent that has less severe side effects than fludarabine, by minimizing cytotoxicity that results from off-target effects. In the longer term, an accumulation of structural information on this kind will enable the rational refinement of individual therapeutic nucleotide analogues so that they target specific combinations of intracellular enzymes, thereby modulating their effect in vivo.

\section{EXPERIMENTAL METHODS}

Nucleotides and Nucleotide Analogues. 2F-ATP (NU-145S), vidarabine-TP (NU-1111S), fludarabine-TP (NU-10703-10), gemcitabine-TP (NU-1607S), clofarabine-TP (NU-874), cytarabine-TP (NU-1170S), and $\mathrm{N}^{6}$-(6-aminohexyl)-ATP-6FAM (NU-805-6FM) were purchased from Jena Bioscience.

Cloning, Expression, and Protein Purification. Heterodimeric human primase (Pri1-Pri2) was coexpressed in bacteria as full-length $\mathrm{His}_{6}$-tagged Pri1 (amino acids 1 to 420) and Pri2 (1 to 462). Residues 463 to 509 of Pri2 were omitted to minimize proteolytic degradation. These residues are not conserved and are disordered in the crystal structure of full-length human primase. ${ }^{41}$ Primer synthesis assays confirmed that this protein showed identical activity to the wild-type protein (Supplementary Figure 5). Human Pril was produced as either full-length $\mathrm{His}_{6}$-tagged Pril (1 to 420, WT or D109A point mutant) for fluorescence polarization experiments or $\mathrm{His}_{10}$-tagged Pril (1 to 407) for crystallization. Due to exposed hydrophobic patches on both Pri1 and Pri2 that interfered with the analysis, thermal melt experiments were performed using a chimeric construct of human primase (Pril-Pri2 ${ }^{\Delta \mathrm{CTD}}$-Pol $\alpha$ ), comprising Pol $\alpha$ residues 1445 to 1462 (GYSEVNLSKLFAGCAVKS) fused via a 15 residue Gly-Ser-Thr linker to residue N19 of Pri2. In this protein, the tethered Pol $\alpha$ peptide binds to a hydrophobic patch on the $\mathrm{N}$-terminal domain of Pri2, while the Pri1 elongation site is unaffected. ${ }^{35}$

All proteins were expressed in the Rosetta2 (DE3) E. coli strain from the pRSFDuet-1 vector (Novagen). The purification protocol entailed Ni-NTA agarose chromatography (Qiagen), heparin sepharose chromatography (GE Healthcare), His-tag cleavage by TEV protease, and size exclusion chromatography. The size exclusion buffer comprised either $25 \mathrm{mM}$ HEPES pH 7.2, $300 \mathrm{mM} \mathrm{KCl,} 5 \%$ (v/ v) glycerol, and $1 \mathrm{mM}$ TCEP (for Pri1-Pri2) or $25 \mathrm{mM}$ HEPES $\mathrm{pH}$ 7.2, $150 \mathrm{mM} \mathrm{KCl}, 5 \%$ (v/v) glycerol, and $1 \mathrm{mM}$ TCEP (for Pril). Purified proteins were concentrated, and aliquots were flash frozen in liquid nitrogen and then stored at $-80{ }^{\circ} \mathrm{C}$. Final yields of protein were $2 \mathrm{mg}$ per liter of culture for Pril and $5 \mathrm{mg}$ per liter of culture for Pri1-Pri2.

Crystallization and X-ray Crystallography. Apo Pril (1 to 407) was crystallized by vapor diffusion at $19^{\circ} \mathrm{C}$, by mixing $1 \mu \mathrm{L}$ of $150 \mu \mathrm{M}$ Pril with $1 \mu \mathrm{L}$ of crystallization buffer: $0.1 \mathrm{M}$ Bis Tris propane $\mathrm{pH} 6.5,24 \%$ (v/v) PEG 3350, $0.15 \mathrm{M} \mathrm{NaF}$. Diffraction data were collected at SOLEIL synchrotron (beamline PROXIMA 1). The protein crystallized in space group $P 4_{3} 2_{1} 2$, with one copy of Pril in the asymmetric unit. Diffraction data were indexed, integrated, and scaled using $\mathrm{XDS}^{49}$ and the structure was solved by molecular 
replacement in Phaser $^{50}$ using 4BPU as the search model. ${ }^{35}$ The model was completed by alternating between cycles of manual rebuilding in $\operatorname{Coot}^{51}$ and structure refinement in PhenixRefine. ${ }^{52}$ Unfortunately, while these crystals diffracted to high resolution (1.5 $\AA$ ), they were often multiple and/or poorly reproducible, and the crystallization condition was therefore optimized for the nucleotide soaking experiments. Pril was subsequently crystallized by vapor diffusion at $19^{\circ} \mathrm{C}$, by mixing $1.5 \mu \mathrm{L}$ of $150 \mu \mathrm{M}$ Pril with $1 \mu \mathrm{L}$ of crystallization buffer: 23\% (v/v) PEG 3350, 10\% (v/v) ethylene glycol, $200 \mathrm{mM} \mathrm{Na} / \mathrm{K}$ tartrate. Crystals were soaked overnight in crystallization buffer containing $500 \mu \mathrm{M}$ nucleotide (ATP, dATP, 2FATP, vidarabine-TP, or fludarabine-TP) and $500 \mu \mathrm{M} \mathrm{MnCl}_{2}$. Diffraction data were collected at beamlines I24 (ATP, 2F-ATP, and vidarabine-TP), I04-1 (dATP), and I02 (fludarabine-TP) of the Diamond Light Source, UK. The protein crystallized in space group C222 1 , with two copies of Pril in the asymmetric unit (Table 1). The apo Pril structure described above was used as the molecular replacement model. Ligand restraints were generated using grade (Global Phasing Ltd.). Data were processed, and the model was refined as described above. Owing to poor electron density, the following residues were considered disordered and omitted from the final model: apo Pril (chain A: 360-381); Pril.ATP (chain A: 1-2, 360-381, 407; chain E: 1, 360-381, 407), Pril.dATP (chain A: 1-4, 361-379; chain E: 1, 361-381), Pri1.2F-ATP (chain A: 1-5, 361379; chain E: 1-3, 361-381, 407), Pril.vidarabine-TP (chain A: 1-5, 362-379; chain D: 1, 361-381), Pril.fludarabine-TP (chain A: 1-5, 361-380; chain E: 1-3, 360-381).

Fluorescence-Based Primase Activity Assays. Time-course RNA primer synthesis assays were performed in triplicate in 96 well plate format. Each well contained $1 \mu \mathrm{M}$ Pri1-Pri2 and $200 \mathrm{nM}$ ssDNA (5'-GTTGTCCATTATGTCCTACCTCGTGCTCCT) in $25 \mathrm{mM}$ HEPES pH 7.0, $120 \mathrm{mM} \mathrm{NaCl}, 1 \mathrm{mM}$ TCEP, $5 \mathrm{mM} \mathrm{MgCl}_{2}$ (or $1 \mathrm{mM}$ $\mathrm{MnCl}_{2}$ ). Reactions were initiated by the addition of $20 \mu \mathrm{M}$ of each ribonucleotide (ATP, CTP, GTP, and UTP) and $20 \mu \mathrm{M}$ nucleotide analogue (ATP, dATP, 2F-ATP, vidarabine-TP, or fludarabine-TP), to give a final reaction volume of $25 \mu \mathrm{L}$. The plate was incubated at 37 ${ }^{\circ} \mathrm{C}$ in the presence of $\mathrm{MgCl}_{2}$ or $25{ }^{\circ} \mathrm{C}$ in the presence of $\mathrm{MnCl}_{2}$. Reactions were quenched at the indicated time points by the addition of $25 \mu \mathrm{L}$ of a 1:100 dilution of PicoGreen (Thermo Fisher Scientific) in $25 \mathrm{mM}$ Tris $\mathrm{pH} 8.0$ and $20 \mathrm{mM}$ EDTA. Following incubation of the plate at $25{ }^{\circ} \mathrm{C}$ for $10 \mathrm{~min}$, fluorescence intensity measurements were recorded in a PHERAstar Plus multidetection plate reader (BMG Labtech) equipped with fluorescence intensity optic module $\left(\lambda_{\text {ex }}=485 \mathrm{~nm} ; \lambda_{\text {em }}=520 \mathrm{~nm}\right)$. Each data point is the mean of 20 flashes per well. The voltage gain was set by adjusting the fluorescence intensity of a well containing protein, nucleotide, and 30-mer dsDNA (ssDNA as above, with annealed complementary strand), to $90 \%$ of the maximum measurable intensity.

Gel-Based Primase Activity Assays. Each $30 \mu \mathrm{L}$ reaction contained $20 \mathrm{mM}$ Tris- $\mathrm{HCl} \mathrm{pH}$ 7.5, $50 \mathrm{mM} \mathrm{K}(\mathrm{OAc}), 1 \mathrm{mM}$ DTT, 0.5 mM NTP, $0.5 \mu \mathrm{M}$ ssDNA or annealed DNA-RNA template, $0.5 \mu \mathrm{M}$ Pri1-Pri2, the indicated concentration of nucleotide analogue and 10 $\mathrm{mM} \mathrm{Mg}(\mathrm{OAc})_{2}$. Reactions were incubated at $37{ }^{\circ} \mathrm{C}$ for the indicated time to allow primer synthesis to occur and then terminated by the addition of $30 \mu \mathrm{L}$ of buffer comprising $95 \%$ formamide and $25 \mathrm{mM}$ EDTA. Samples were heated to $70{ }^{\circ} \mathrm{C}$ for $2 \mathrm{~min}$ and then loaded onto a $18 \%$ urea-polyacrylamide gel, which was run at $500 \mathrm{~V}$ for $90 \mathrm{~min}$ in $0.5 \times$ TBE buffer. Gels were stained in $0.5 \times$ TBE buffer containing a 1:10000 dilution of Sybr Gold Stain (Thermo Fisher Scientific), for 30 min with shaking. Reaction products were visualized by scanning with a $473 \mathrm{~nm}$ laser (Typhoon FLA 9000, GE Healthcare).

Fluorescence Anisotropy-Based Nucleotide Binding Experiments. Binding experiments were performed in triplicate in 96 well plate format. Each well contained $30 \mathrm{nM}$ 6FAM-labeled ATP in 25 mM HEPES pH 7.0, $120 \mathrm{mM} \mathrm{NaCl}, 1 \mathrm{mM}$ TCEP, and $1 \mathrm{mM} \mathrm{\textrm {MnCl } _ { 2 }}$ (or $1 \mathrm{mM} \mathrm{MgCl}$ ). Pril was added in increasing concentrations, ranging from 0 to $25.4 \mu \mathrm{M}$ (in the presence of $\mathrm{MgCl}_{2}$ ) or 0 to $5.0 \mu \mathrm{M}$ (in the presence of $\mathrm{MnCl}_{2}$ ). Fluorescence anisotropy measurements were recorded in a PHERAstar Plus multidetection plate reader (BMG Labtech) equipped with a fluorescence polarization optic module $\left(\lambda_{\mathrm{ex}}=485 \mathrm{~nm} ; \lambda_{\mathrm{em}}=520 \mathrm{~nm}\right)$, at $25^{\circ} \mathrm{C}$. Each data point is the mean of 200 flashes per well. The voltage gain was set by adjusting the target $\mathrm{mP}$ values of 6FAM-labeled ATP relative to that of fluorescein $(35 \mathrm{mP})$. Monte Carlo curve fitting was performed in ProFit (QuantumSoft).

Fluorescence Anisotropy-Based Competition Binding Experiments. Competition binding experiments were performed in triplicate in 96 well plate format. Each well contained $30 \mathrm{nM}$ 6FAMlabeled ATP and $1.5 \mu \mathrm{M}$ Pril, and nucleotide analogue was titrated in increasing concentrations, from 0 to $200 \mu \mathrm{M}$. Binding buffer comprised $25 \mathrm{mM}$ HEPES $\mathrm{pH} 7.0,120 \mathrm{mM} \mathrm{NaCl}, 1 \mathrm{mM}$ TCEP, and $1 \mathrm{mM} \mathrm{MnCl}$. Fluorescence anisotropy measurements were recorded in a PHERAstar Plus multidetection plate reader (BMG Labtech), as described above. Monte Carlo curve fitting was performed in ProFit (QuantumSoft). $K_{1 / 2}$ values are reported, representing the concentration of ligand required to reduce the signal to half its original value.

Thermal Denaturation. Reactions were performed in quadruplicate, in 96 well plate format. Each well contained $6.3 \mu \mathrm{M}$ PrilPri $2^{\Delta \mathrm{CTD}}$-Pol $\alpha$ chimera, $500 \mu \mathrm{M} \mathrm{MnCl}_{2}, 500 \mu \mathrm{M}$ nucleotide, and $5 \times$ SYPRO orange dye (Sigma-Aldrich), in a reaction buffer comprising $25 \mathrm{mM}$ HEPES pH 7.0, $150 \mathrm{mM} \mathrm{NaCl}$, and $1 \mathrm{mM}$ TCEP. Heating was performed in a CFX Connect Real-time PCR detection system with a 96-well reaction module (Bio-Rad), using a ramp rate of 0.2 ${ }^{\circ} \mathrm{C} \cdot \mathrm{min}^{-1}$. The negative of the first derivative of the fluorescence signal was plotted against temperature, and the melting temperature $\left(T_{\mathrm{m}}\right)$ was estimated from the local minimum of the curve peak.

\section{ASSOCIATED CONTENT}

\section{Supporting Information}

The Supporting Information is available free of charge on the ACS Publications website at DOI: 10.1021/acschembio.9b00367.

Figure 1, effect of divalent metals on primase activity and nucleotide binding; Figure 2, Fo-Fc omit maps; Figure 3, effect of cordycepin-TP on primase activity; Figure 4, effect of cytarabine-TP, clofarabine-TP, and gemcitabine-TP on primase activity; and Figure 5, C-terminal truncation of Pri2 has no affect on primase activity (PDF)

\section{Accession Codes}

The coordinates and structure factors for the crystal structures presented in this paper have been deposited in the PDB under accession codes 6R4S (Pril.ATP), 6R5D (Pri1.dATP), 6R5E (Pril.2F-ATP), 6R4T (Pril.vidarabine-TP), 6R4U (Pril.fludarabine-TP), and 6RB4 (apo Pri1).

\section{AUTHOR INFORMATION}

\section{Corresponding Author}

*Phone: +44 1223 333652. E-mail: mlk26@cam.ac.uk.

ORCID

Luca Pellegrini: 0000-0002-9300-497X

Mairi L. Kilkenny: 0000-0002-7280-8522

\section{Author Contributions}

M.L.K. designed the experiments and analyzed results. M.L.K. and S.H. performed the competition binding experiments and fluorescence-based primer synthesis assays. M.L.K. and I.R.S. performed the cytarabine-TP, gemcitabine-TP, and clofarabine-TP primer synthesis assays. M.J.B. optimized the gelbased primer synthesis assay and carried out the initial fludarabine-TP and vidarabine-TP studies. M.L.K. and N.J.R. collected the X-ray diffraction data. L.P. and M.L.K. conceived the project and directed the research. M.L.K. wrote the manuscript, with contributions from all authors. 


\section{Notes}

The authors declare no competing financial interest.

\section{ACKNOWLEDGMENTS}

We thank Diamond Light Source for access to beamlines I02, I04-1, and I24 (MX9537) that contributed to the results presented here. We also acknowledge SOLEIL for the provision of synchrotron radiation facilities and would like to thank the staff of beamline PROXIMA1 for assistance. We are grateful to the Facility Managers of the Crystallographic X-ray Facility (D. Chirgadze) and the Biophysics Facility (K. Stott) at the Department of Biochemistry, University of Cambridge for their assistance in using these facilities. We are grateful to $\mathrm{J}$. Maman for expert advice on all fluorescence measurements. This work was funded by a Wellcome Trust Investigator Award (104641/Z/14/Z) to L.P. S.H. was funded by a BoehringerIngelheim Fonds $\mathrm{PhD}$ Fellowship, Janggen-Pöhn-Stiftung Award, and Swiss National Science Foundation Award.

\section{REFERENCES}

(1) Pellegrini, L., and Costa, A. (2016) New Insights into the Mechanism of DNA Duplication by the Eukaryotic Replisome. Trends Biochem. Sci. 41, 859-871.

(2) Frick, D. N., and Richardson, C. C. (2001) DNA Primases. Annu. Rev. Biochem. 70, 39-80.

(3) Lucchini, G., Francesconi, S., Foiani, M., Badaracco, G., and Plevani, P. (1987) Yeast DNA polymerase-DNA primase complex; cloning of PRI 1, a single essential gene related to DNA primase activity. EMBO J. 6, 737-742.

(4) Cloutier, S., Hamel, H., Champagne, M., and Yotov, W. V. (1997) Mapping of the human DNA primase 1 (PRIM1) to chromosome 12q13. Genomics 43, 398-401.

(5) Yotov, W. V., Hamel, H., Rivard, G.-E., Champagne, M. A., Russo, P. A., Leclerc, J.-M., Bernstein, M. L., and Levy, E. (1999) Amplifications of DNA Primase 1 (PRIM1) in Human Osteosarcoma. Genes, Chromosomes Cancer 26, 62-69.

(6) Lee, W., Chen, L., Lee, C., Huang, C., Ho, Y., Yang, P., Ho, C., Chang, H., Lin, I., Chang, H., Liu, Y., Wu, C., and Tu, S. (2019) DNA primase polypeptide 1 (PRIM1) involves in estrogen-induced breast cancer formation through activation of the G2/M cell cycle checkpoint. Int. J. Cancer 144, 615-630.

(7) Tzelepis, K., Koike-Yusa, H., De Braekeleer, E., Li, Y., Metzakopian, E., Dovey, O. M., Mupo, A., Grinkevich, V., Li, M., Mazan, M., Gozdecka, M., Ohnishi, S., Cooper, J., Patel, M., McKerrell, T., Chen, B., Domingues, A. F., Gallipoli, P., Teichmann, S., Ponstingl, H., McDermott, U., Saez-Rodriguez, J., Huntly, B. J. P., Iorio, F., Pina, C., Vassiliou, G. S., and Yusa, K. (2016) A CRISPR Dropout Screen Identifies Genetic Vulnerabilities and Therapeutic Targets in Acute Myeloid Leukemia. Cell Rep. 17, $1193-1205$.

(8) Hocke, S., Guo, Y., Job, A., Orth, M., Ziesch, A., Lauber, K., De Toni, E. N., Gress, T. M., Herbst, A., Göke, B., and Gallmeier, E. (2016) A synthetic lethal screen identifies ATR-inhibition as a novel therapeutic approach for POLD1-deficient cancers. Oncotarget 7, $7080-7095$.

(9) Job, A., Schmitt, L. M., von Wenserski, L., Lankat-Buttgereit, B., Gress, T. M., Buchholz, M., and Gallmeier, E. (2018) Inactivation of PRIM1 Function Sensitizes Cancer Cells to ATR and CHK1 Inhibitors. Neoplasia 20, 1135-1143.

(10) Plunkett, W., and Saunders, P. P. (1991) Metabolism and action of purine nucleoside analogs. Pharmacol. Ther. 49, 239-268.

(11) Jordheim, L. P., Durantel, D., Zoulim, F., and Dumontet, C. (2013) Advances in the development of nucleoside and nucleotide analogues for cancer and viral diseases. Nat. Rev. Drug Discovery 12, 447-464.

(12) Huang, P., Sandoval, A., Van Den Neste, E., Keating, M. J., and Plunkett, W. (2000) Inhibition of RNA transcription: a biochemical mechanism of action against chronic lymphocytic leukemia cells by fludarabine. Leukemia 14, 1405-1413.

(13) De Clercq, E., and Li, G. (2016) Approved antiviral drugs over the past 50 years. Clin. Microbiol. Rev. 29, 695-747.

(14) Chun, H. G., Leyland-Jones, B., and Cheson, B. D. (1991) Fludarabine Phosphate: A Synthetic Purine Antimetabolite With Significant Activity Against Lymphoid Malignancies. J. Clin. Oncol. 9, $175-188$.

(15) Tamamyan, G., Kadia, T., Ravandi, F., Borthakur, G., Cortes, J., Jabbour, E., Daver, N., Ohanian, M., Kantarjian, H., and Konopleva, M. (2017) Frontline treatment of acute myeloid leukemia in adults. Crit. Rev. Oncol. Hematol. 110, 20-34.

(16) Lukenbill, J., and Kalaycio, M. (2013) Fludarabine: A review of the clear benefits and potential harms. Leuk. Res. 37, 986-994.

(17) Fidias, P., Chabner, B. A., and Grossbard, M. L. (1996) Purine analogs for the treatment of low-grade lymphoproliferative disorders. Oncologist 1, 125-139.

(18) Parker, W. B., Bapat, A. R., Shen, J., Townsend, A. J., and Cheng, Y. (1988) Interaction of 2-Halogenated dATP Analogs (F, Cl, and $\mathrm{Br}$ ) with Human DNA Polymerases, DNA Primase and Ribonucleotide Reductase. Mol. Pharmacol. 34, 485-491.

(19) Tseng, W. C., Derse, D., Cheng, Y. C., Brockman, R. W., and Bennett, L. L. (1982) In vitro biological activity of 9-beta-Darabinofuranosyl-2-fluoroadenine and the biochemical actions of its triphosphate on DNA polymerases and ribonucleotide reductase from HeLa cells. Mol. Pharmacol. 21, 474-477.

(20) White, E. L., Shaddix, S. C., Brockman, R. W., and Bennett, L. L. (1982) Comparison of the Actions of 9- $\beta$-D-Arabinofuranosyl-2fluoroadenine and 9- $\beta$-D-Arabinofuranosyladenine on Target Enzymes from Mouse Tumor Cells. Cancer Res. 42, 2260-2664.

(21) Yang, S., Huang, P., Plunkett, W., Becker, F. F., and Chan, J. Y. H. (1992) Dual Mode of Inhibition of Purified DNA Ligase I from Human Cells by $9-\beta$-D-Arabinofuranosyl-2-fluoroadenine Triphosphate. J. Biol. Chem. 267, 2345-2349.

(22) Huang, P., Chubb, S., and Plunkett, W. (1990) Termination of DNA synthesis by $9-\beta$-D-arabinofuranosyl-2-fluoroadenine. A mechanism for cytotoxicity. J. Biol. Chem. 265, 16617-16625.

(23) Wisitpitthaya, S., Zhao, Y., Long, M. J. C., Li, M., Fletcher, E. A., Blessing, W. A., Weiss, R. S., and Aye, Y. (2016) Cladribine and Fludarabine Nucleotides Induce Distinct Hexamers Defining a Common Mode of Reversible RNR Inhibition. ACS Chem. Biol. 11, 2021-2032.

(24) Huang, P., and Plunkett, W. (1991) Action of 9- $\beta$-DArabinofuranosyl-2-fluoroadenine on RNA Metabolism. Mol. Pharmacol. 39, 449-455.

(25) Plunkett, W., Chubb, S., Alexander, L., and Montgomery, J. A. (1980) Comparison of the toxicity and metabolism of $9-\beta$-darabinofuranosyl-2-fluoroadenine and 9- $\beta$-d-arabinofuranosyladenine in human lymphoblastoid cells. Cancer Res. 40, 2349-2355.

(26) Dicioccio, R. A., and Srivastava, B. I. S. (1977) Kinetics of Inhibition of Deoxynucleotide-Polymerizing Enzyme Activities from Normal and Leukemic Human Cells by $9-\beta$-D-Arabinofuranosyladenine $5{ }^{\prime}$-Triphosphate and 1- $\beta$-D-Arabinofuranosylcytosine $5{ }^{\prime}$-Triphosphate. Eur. J. Biochem. 79, 411-418.

(27) Yoshida, S., Suzuki, R., Masaki, S., and Koiwai, O. (1985) Arabinosylnucleoside 5'-triphosphate inhibits DNA primase of calf thymus. J. Biochem. 98, 427-433.

(28) Parker, W. B., and Cheng, Y. (1986) Inhibition of DNA Primase by Nucleoside Triphosphates and Their Arabinofuranosyl Analogs. Mol. Pharmacol. 31, 146-151.

(29) Catapano, C. V., Perrino, F. W., and Fernandes, D. J. (1993) Primer RNA Chain Termination Induced by 9-beta-D-Arabinofuranosyl-2-fluoroadenine 5'-Triphosphate. J. Biol. Chem. 268, 71797185 .

(30) Harrington, C., and Perrino, F. W. (1995) The Effects of Cytosine Arabinoside on RNA-primed DNA Synthesis by DNA Polymerase $\alpha$-Primase. J. Biol. Chem. 270, 26664-26669.

(31) Kuchta, R. D., Ilsley, D., Kravig, K. D., Schubert, S., and Harris, B. (1992) Inhibition of DNA Primase and Polymerase $\alpha$ by 
arabinofuranosylnucleoside triphosphates and related compounds. Biochemistry 31, 4720-4728.

(32) Kuchta, R. D., and Willhelm, L. (1991) Inhibition of DNA Primase by 9-beta-D-Arabinofuranosyladenosine triphosphate. Biochemistry 30, 797-803.

(33) Catapano, C. V., Chandler, K. B., and Fernandes, D. J. (1991) Inhibition of Primer RNA Formation in CCRF-CEM Leukemia Cells by Fludarabine Triphosphate. Cancer Res. 51, 1829-1835.

(34) Moore, C. L., Chiaramonte, M., Higgins, T., and Kuchta, R. D. (2002) Synthesis of Nucleotide Analogues That Potently and Selectively Inhibit Human DNA Primase. Biochemistry 41, 1406614075 .

(35) Kilkenny, M. L., Longo, M. A., Perera, R. L., and Pellegrini, L. (2013) Structures of human primase reveal design of nucleotide elongation site and mode of $\operatorname{Pol} \alpha$ tethering. Proc. Natl. Acad. Sci. U. S. A. 110, 15961-15966.

(36) Vaithiyalingam, S., Arnett, D. R., Aggarwal, A., Eichman, B. F., Fanning, E., and Chazin, W. J. (2014) Insights into eukaryotic primer synthesis from structures of the $\mathrm{p} 48$ subunit of human DNA primase. J. Mol. Biol. 426, 558-569.

(37) Koepsell, S. A., Hanson, S., Hinrichs, S. H., and Griep, M. A. (2005) Fluorometric assay for bacterial primases. Anal. Biochem. 339, $353-355$.

(38) Kirk, B. W., and Kuchta, R. D. (1999) Human DNA primase: anion inhibition, manganese stimulation, and their effects on in vitro start-site selection. Biochemistry 38, 10126-10134.

(39) Copeland, W. C., Lam, N. K., and Wang, T. S. F. (1993) Fidelity studies of the human DNA polymerase $\alpha$. J. Biol. Chem. 268, 11041-11049.

(40) Richardson, K. A., Vega, T. P., Richardson, F. C., Moore, C. L., Rohloff, J. C., Tomkinson, B., Bendele, R. A., and Kuchta, R. D. (2004) Polymerization of the triphosphates of $\mathrm{AraC}, 2^{\prime}, 2^{\prime}$ difluorodeoxycytidine $(\mathrm{dFdC})$ and OSI-7836 (T-araC) by human DNA polymerase $\alpha$ and DNA primase. Biochem. Pharmacol. 68, 2337-2346.

(41) Baranovskiy, A. G., Babayeva, N. D., Zhang, Y., Gu, J., Suwa, Y., Pavlov, Y. I., and Tahirov, T. H. (2016) Mechanism of Concerted RNA-DNA Primer Synthesis by the Human Primosome. J. Biol. Chem. 291, 10006-10020.

(42) Copeland, W. C., and Wang, T. S. F. (1993) Enzymatic characterization of the individual mammalian primase subunits reveals a biphasic mechanism for initiation of DNA replication. J. Biol. Chem. 268, 26179-26189.

(43) Klinge, S., Hirst, J., Maman, J. D., Krude, T., and Pellegrini, L. (2007) An iron-sulfur domain of the eukaryotic primase is essential for RNA primer synthesis. Nat. Struct. Mol. Biol. 14, 875-877.

(44) Zerbe, L. K., and Kuchta, R. D. (2002) The p58 subunit of human DNA primase is important for primer initiation, elongation, and counting. Biochemistry 41, 4891-4900.

(45) Copeland, W. C., and Tan, X. (1995) Active site mapping of the catalytic mouse primase subunit by alanine scanning mutagenesis. J. Biol. Chem. 270, 3905-3913.

(46) Gandhi, V., and Plunkett, W. (2002) Cellular and clinical pharmacology of fludarabine. Clin. Pharmacokinet. 41, 93-103.

(47) Srikanth, V., Batista, V. S., Ji, X., Reiss, K., Tofoleanu, F., Cinatl, J., Buzovetsky, O., Ferreirós, N., Kaderali, L., Xiong, Y., Keppler, O. T., Schneider, C., Thomas, D., Geisslinger, G., and Knecht, K. M. (2018) The structural basis for cancer drug interactions with the catalytic and allosteric sites of SAMHD1. Proc. Natl. Acad. Sci. U. S. A. 115, E10022-E10031.

(48) Tokarsky, E. J., Wallenmeyer, P. C., Phi, K. K., and Suo, Z. (2017) Significant impact of divalent metal ions on the fidelity, sugar selectivity, and drug incorporation efficiency of human PrimPol. DNA Repair 49, 51-59.

(49) Kabsch, W. (2010) XDS. Acta Crystallogr., Sect. D: Biol. Crystallogr. 66, 125-132.

(50) McCoy, A. J., Grosse-Kunstleve, R. W., Adams, P. D., Winn, M. D., Storoni, L. C., and Read, R. J. (2007) Phaser crystallographic software. J. Appl. Crystallogr. 40, 658-674.
(51) Emsley, P., Lohkamp, B., Scott, W. G., and Cowtan, K. (2010) Features and development of Coot. Acta Crystallogr., Sect. D: Biol. Crystallogr. 66, 486-501.

(52) Adams, P. D., Afonine, P. V., Bunkóczi, G., Chen, V. B., Davis, I. W., Echols, N., Headd, J. J., Hung, L. W., Kapral, G. J., GrosseKunstleve, R. W., McCoy, A. J., Moriarty, N. W., Oeffner, R., Read, R. J., Richardson, D. C., Richardson, J. S., Terwilliger, T. C., and Zwart, P. H. (2010) PHENIX: A comprehensive Python-based system for macromolecular structure solution. Acta Crystallogr., Sect. D: Biol. Crystallogr. 66, 213-221.

(53) Pettersen, E. F., Goddard, T. D., Huang, C. C., Couch, G. S., Greenblatt, D. M., Meng, E. C., and Ferrin, T. E. (2004) UCSF Chimera - A visualization system for exploratory research and analysis. J. Comput. Chem. 25, 1605-1612. 